\title{
Preparation of Tungsten Alkyl Alkylidene Alkylidyne Complexes and Kinetic Studies of Their Formation
}

Laurel A. Morton, Shujian Chen, He Qiu, Zi-Ling Xue*

Department of Chemistry, The University of Tennessee, Knoxville, TN 37996, USA. Fax: 1865-974-3454; Tel: 1-865-974-3443; E-mail: xue@ion.chem.utk.edu

\section{Supporting Information}




\section{Considerations of the Kinetics of the Formation of 2}

(A) In Scheme 4, Path II, an equilibrium mixture of 1a-b quickly reacts with $\mathrm{PMe}_{3}$ to form an adduct (Intermediate $\mathbf{B}$ ), which then undergoes a slow $\alpha$-hydrogen abstraction to give 2.

Path II (Scheme 4)

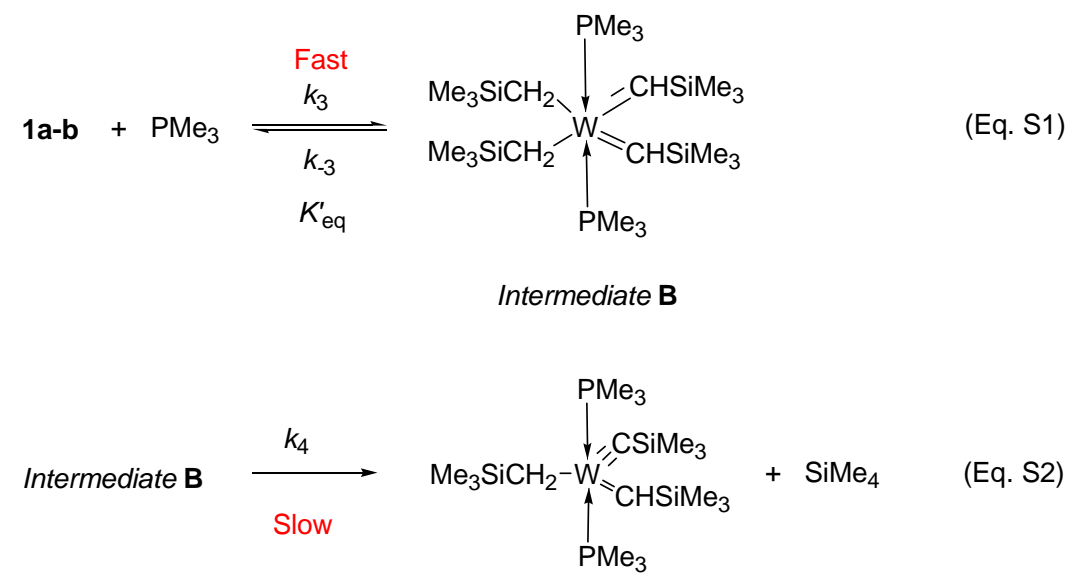

2

The rates of the reaction derived using either the steady-state or pre-equilibrium approximations would be dependent on $C_{\mathrm{PMe}_{3}}$ (Eq. S3).

(a) Using steady-state approximation,

$$
\begin{gathered}
C_{\text {Intermediate B }}=\frac{k_{3}}{k_{-3}+k_{4}} C_{\mathrm{PMe}_{3} C_{1}} \\
d C_{1} / d t=-k_{3} C_{\mathrm{PMe}_{3}} C_{1}+k_{-3} C_{\text {Intermediate B }} \\
\frac{-k_{3} k_{4}}{k_{-3}+k_{4}} C_{\mathrm{PMe}_{3}} C_{1}=k^{\prime} C_{\mathrm{PMe}_{3}} C_{1}
\end{gathered}
$$

(b) Using pre-equilibrium approximation,

$$
\frac{C_{\text {Intermediate } \mathrm{B}}}{\mathrm{C}_{\mathrm{PMe}_{3}} C_{1}}=K_{\text {eq }}^{\prime}
$$

Rate determining step: $\quad$ Rate $=k_{4} K_{\text {eq }} C_{\mathrm{PMe}_{3}} C_{1}=k^{\prime} C_{\mathrm{PMe}_{3}} C_{1}$

$$
\text { Rate }=k^{\prime} C_{\mathrm{PMe}_{3}} C_{1}
$$


(B) Two additional pathways in the formation of 2 (Path III and Path IV) were considered, and they both show the dependence of reaction rates on the concentration of $\mathrm{PMe}_{3}$.

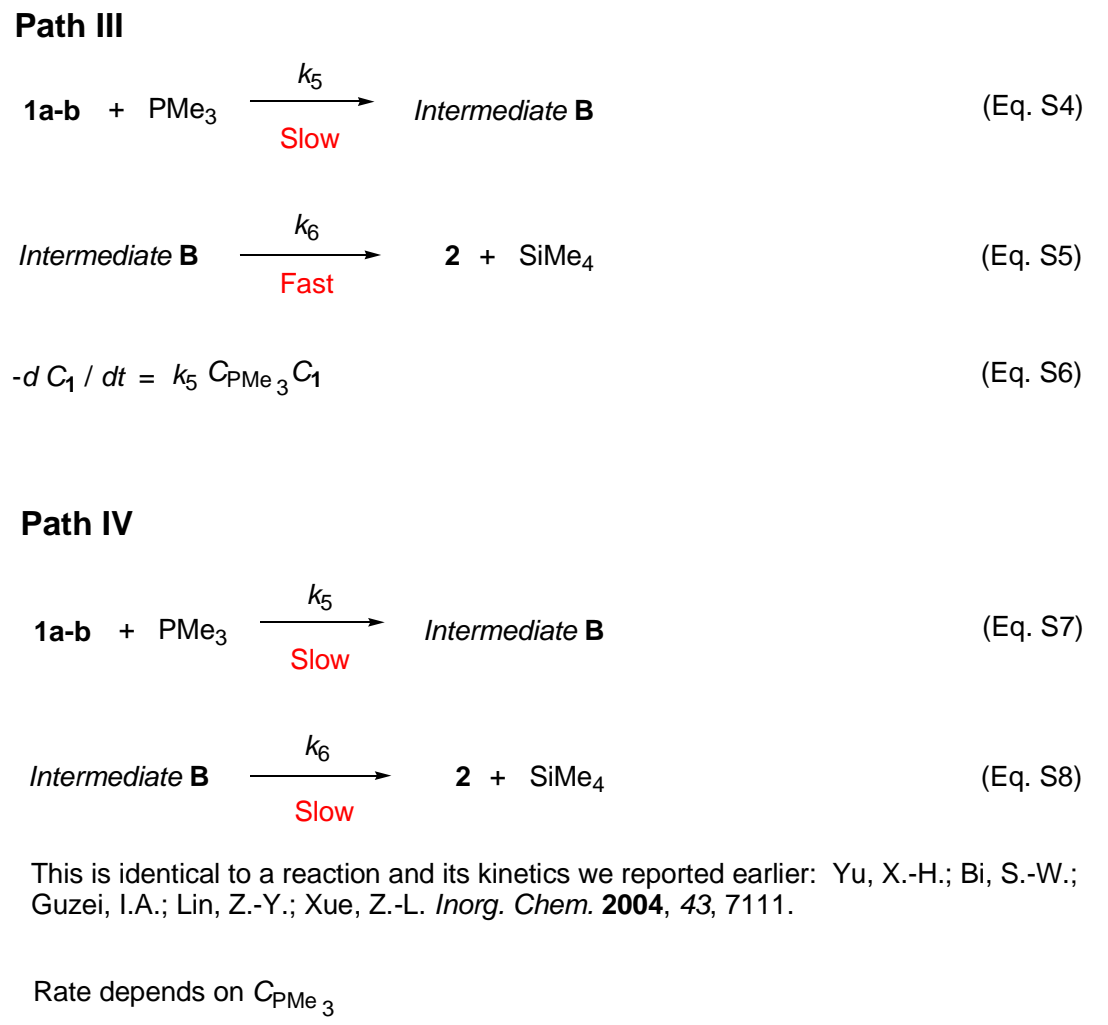




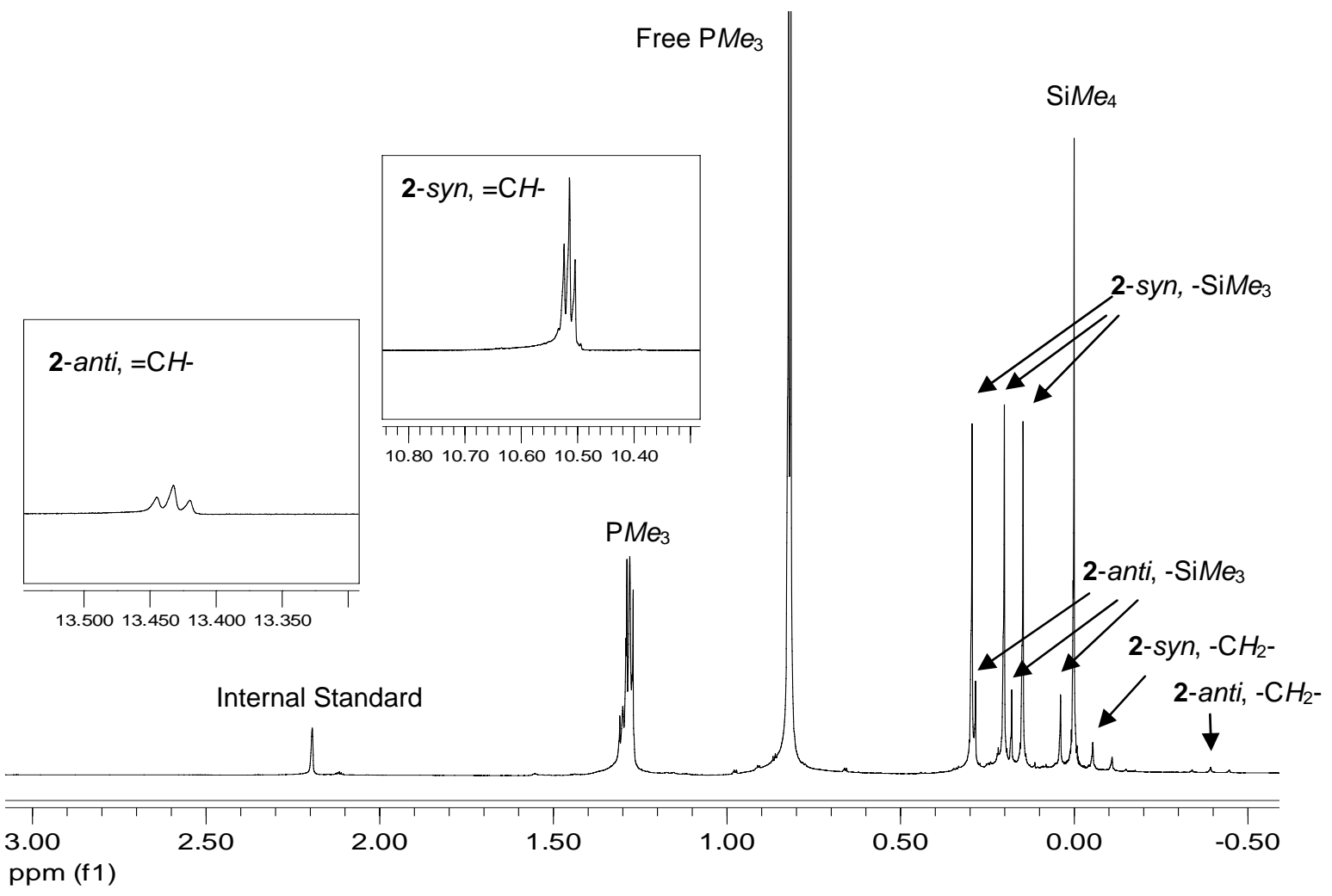

Figure S1. ${ }^{1} \mathrm{H}$ NMR spectrum of a mixture of 2-syn and 2-anti (toluene- $d_{8}$ ). 


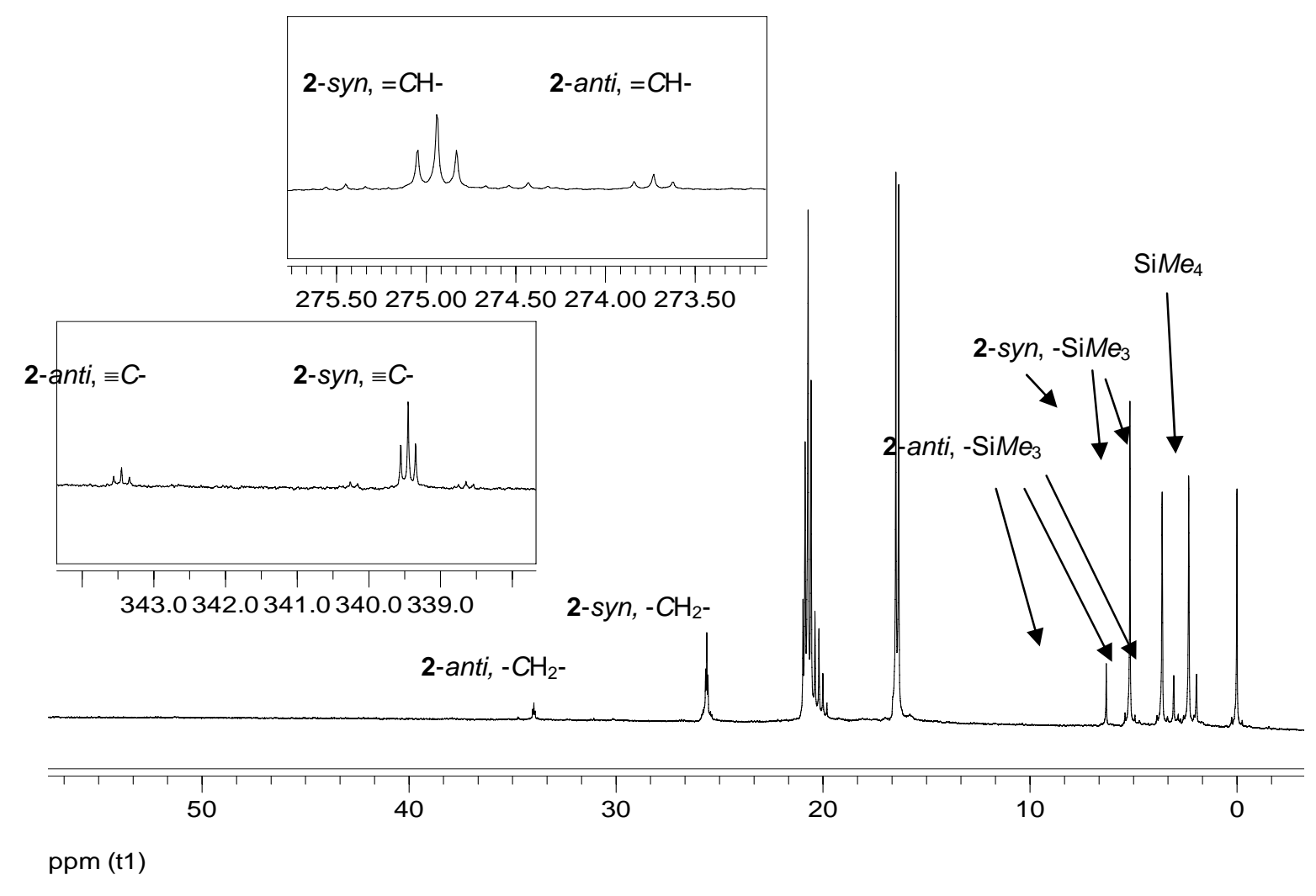

Figure S2. ${ }^{13} \mathrm{C}$ NMR spectrum of a mixture of 2-syn and 2-anti (toluene- $d_{8}$ ). 


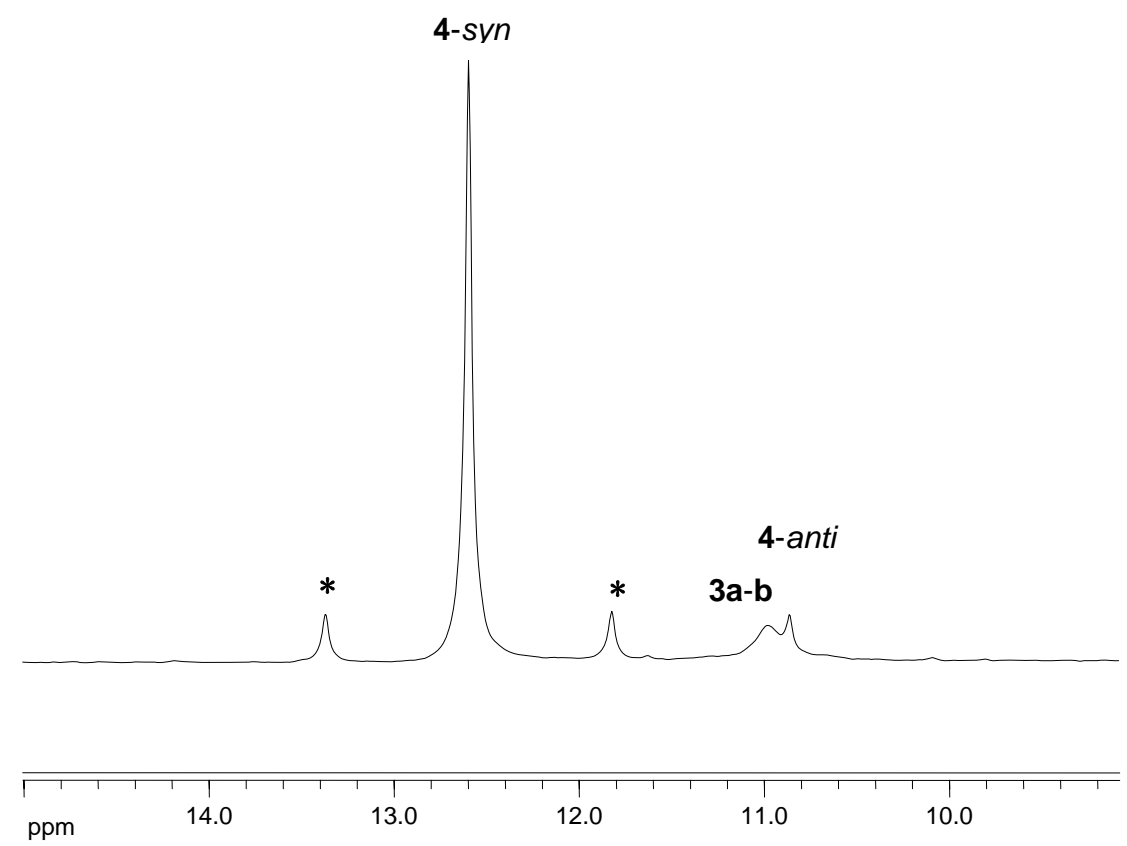

Figure S3. ${ }^{31} \mathrm{P}$ NMR spectrum of 4-syn and 4-anti. A small amount of $\mathbf{3} \mathbf{a}-\mathbf{b}$ is present in solution as a broad peak overlapping with 4-anti. (* indicates W satellites.) 


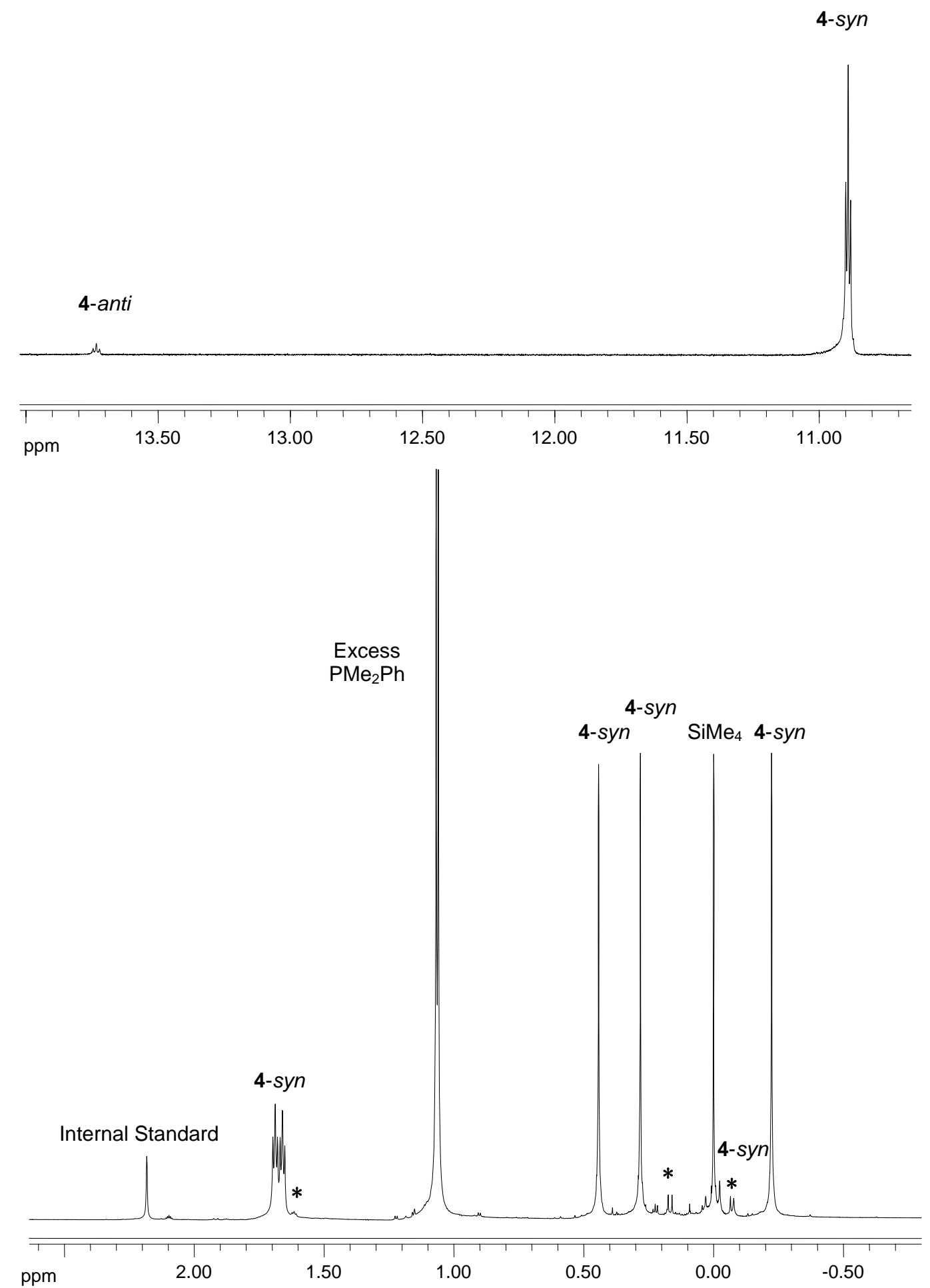

Figure S4. ${ }^{1} \mathrm{H}$ NMR spectrum of 4-syn. (Top) Alkylidene $\mathrm{W}=\mathrm{CHSiMe}$ region for 4-syn and 4-anti. (Bottom) Alkyl and phosphine region. 4-anti is marked by $\left(^{*}\right)$. (I.S. = internal standard 4,4'-dimethylbiphenyl). 

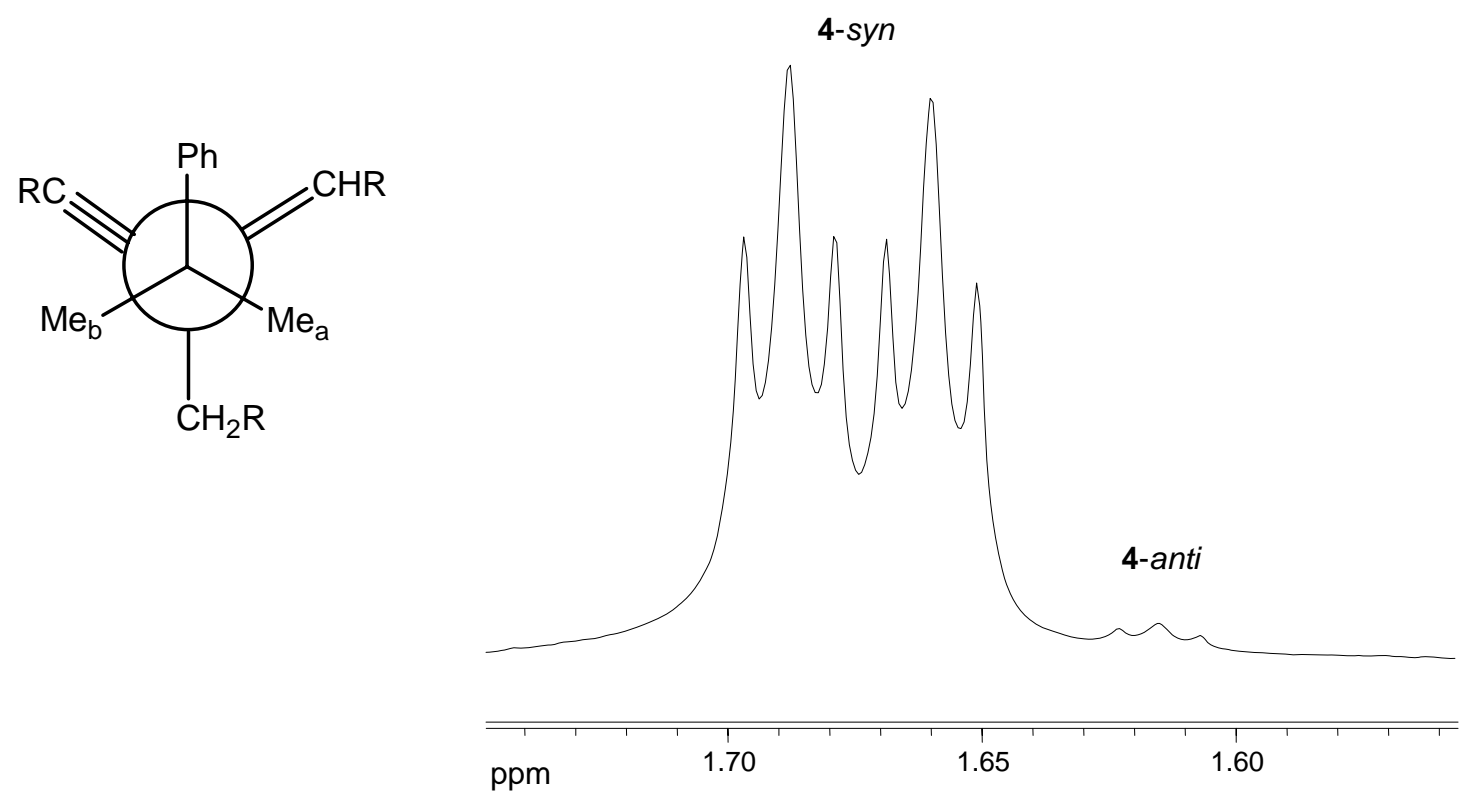

Figure S5. The Newman projection of 4 and the ${ }^{1} \mathrm{H}$ NMR spectrum showing the two methyl resonances in $\mathrm{PMe}_{2} \mathrm{Ph}$ with virtual ${ }^{31} \mathrm{P}-\mathrm{H}$ coupling. 


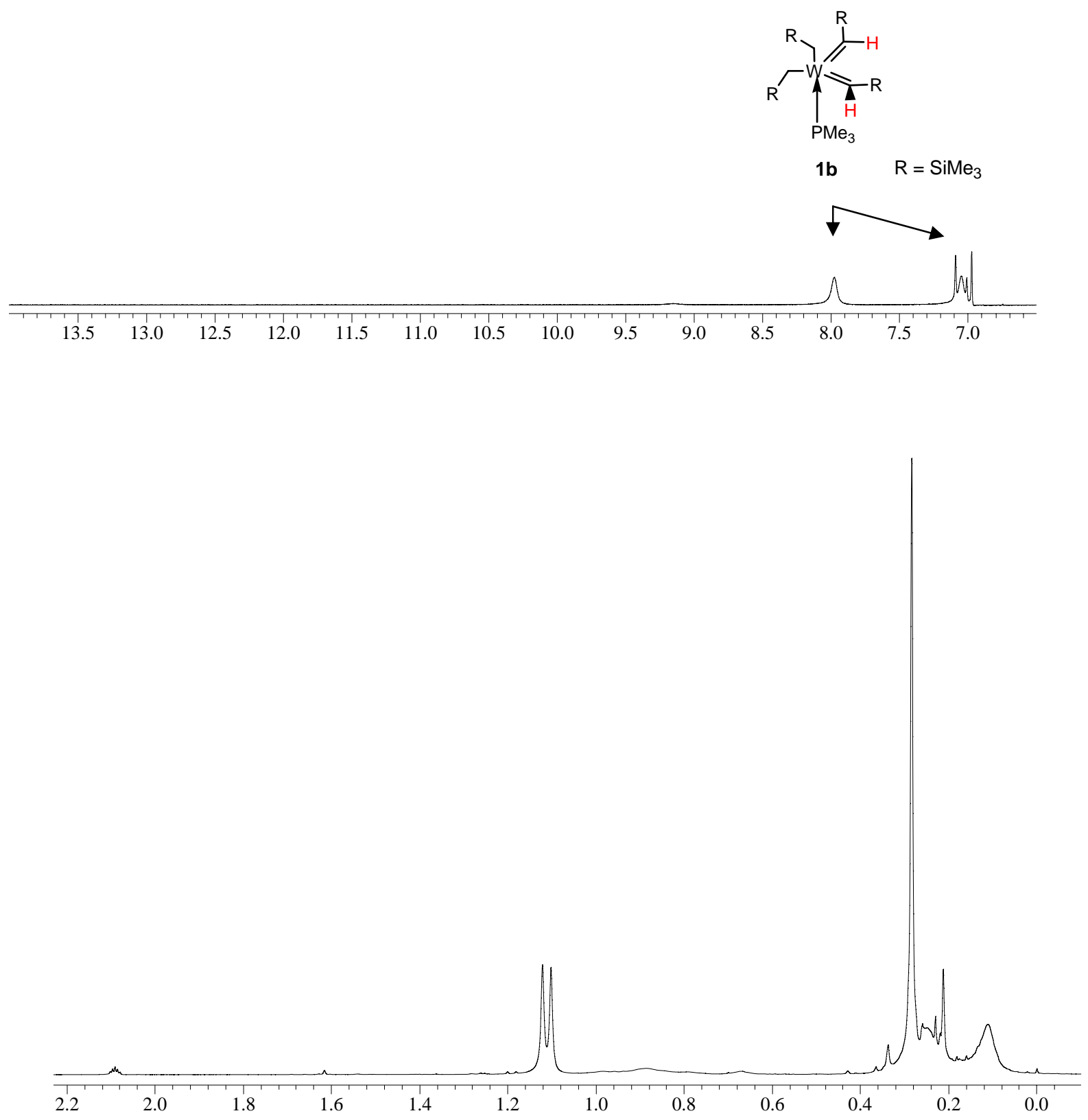

Figure S6. ${ }^{1} \mathrm{H}$ NMR spectrum of $\mathrm{W}\left(\mathrm{CH}_{2} \mathrm{SiMe}_{3}\right)_{2}(=\mathrm{CHSiMe})_{2}\left(\mathrm{PMe}_{3}\right)(\mathbf{1 b})$ in toluene- $d_{8}$ at $23^{\circ} \mathrm{C}$ prior to heating at $68(4){ }^{\circ} \mathrm{C}$ : (Top) Two alkylidene protons; (Bottom) Other protons in $\mathbf{1 b}$. 

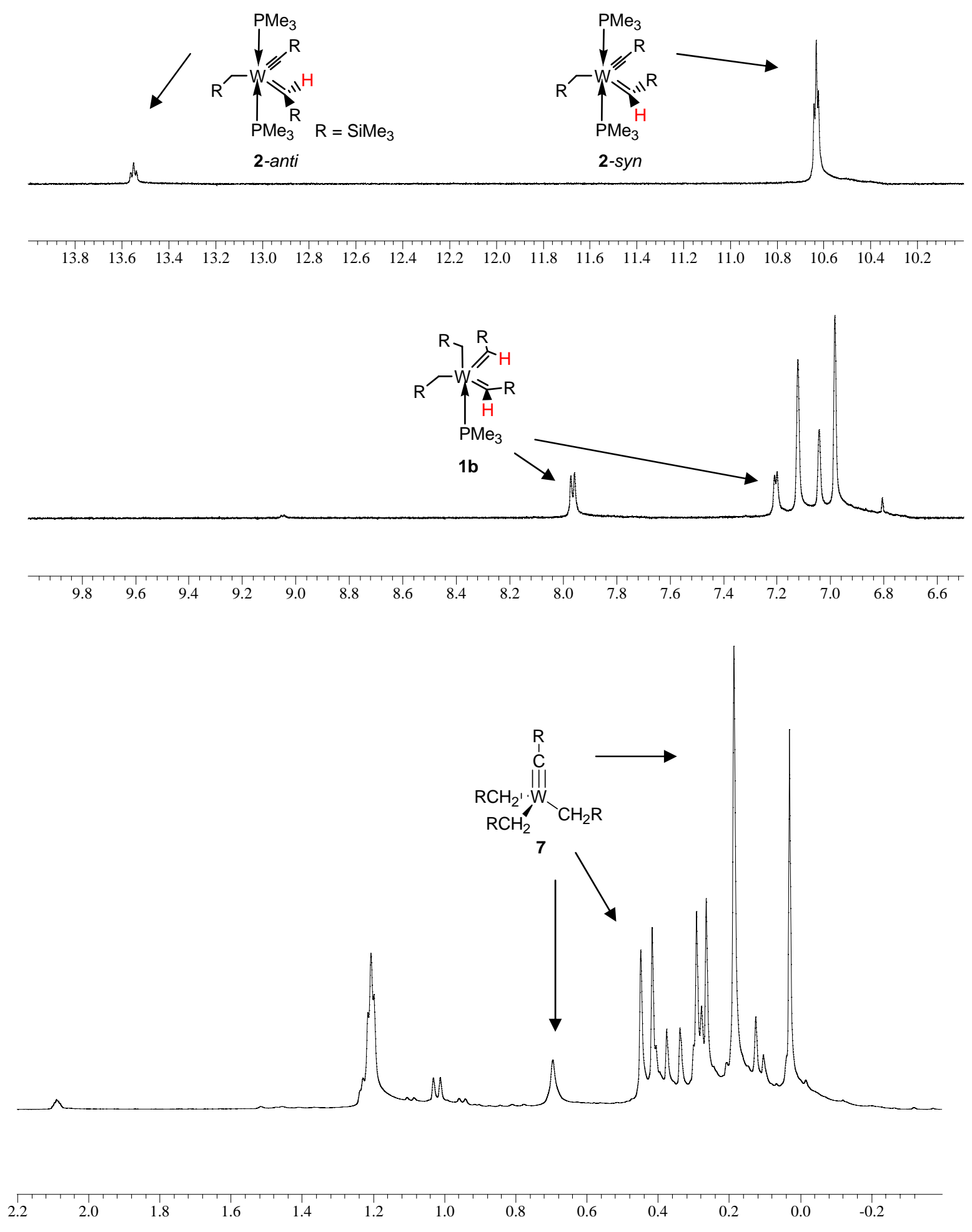

Figure S7. ${ }^{1} \mathrm{H}$ NMR spectra $\left(-20^{\circ} \mathrm{C}\right)$ of $\mathbf{1 b}$ in toluene- $d_{8}$ after heating at ca. $68(4){ }^{\circ} \mathrm{C}$ for $23 \mathrm{~h}$, showing the formation of 2 and 7: (Top) alkylidene protons of 2; (Middle) alkylidene protons of un-reacted $\mathbf{1 b}$; (Bottom) $\mathbf{7}$ and other protons in $\mathbf{1 b}$ and $\mathbf{2}$. 
Table S1. $k_{\text {obs }}$ values at different $C_{\mathrm{PMe}_{3}}$ at $338.2(0.1) \mathrm{K}$

$C_{\mathrm{PMe}_{3}}(\mathrm{M}) \quad 10^{5} k_{\text {obs }}\left(\mathrm{s}^{-1}\right)$

\begin{tabular}{ll}
1.51 & 1.19 \\
1.80 & 1.65 \\
2.42 & 1.61 \\
2.55 & 1.28 \\
3.06 & 1.27 \\
\hline
\end{tabular}

